\title{
FORMAÇÃO CONTINUADA DE PROFESSORES CENTRADA NA ESCOLA: REFLEXÕES TEÓRICAS
}

\author{
ENTRENAMIENTO ESCOLAR CONTINUO DE MAESTROS: \\ REFLEXIONES TEÓRICAS
}

\section{CONTINUOUS SCHOOL TRAINING OF TEACHERS: THEORETICAL REFLECTIONS}

Judenilson Teixeira Amador ${ }^{1}$ amador.macapa@gmail.com

\section{RESUMO}

O texto tem como finalidade realizar reflexões acerca de estudos de teóricos sobre o fenômeno da formação continuada centrada na escola. A pesquisa teórica ora apresentada, faz parte de umas das seções de minha tese doutoral, intitulada "Formação Continuada de Professores do Ensino Fundamental Centrada na Escola: percepções de professores e formadores de melhoria da prática pedagógica", defendida no ano de 2019, pela Universidade Federal do Pará. Para tanto por meio de uma pesquisa bibliográfica buscamos situar o debate conceitual a respeito da formação continuada de professores centrada na escola. Os estudos realizados mostram que a formação continuada de professores centrada na escola é um modelo formativo, que baseia-se nas necessidades formativas dos professores, da escola e da comunidade tendo em vista um processo constante de reflexão da prática educativa, dos saberes docentes, das experiências escolares e a realidade da escola.

PALAVRAS-CHAVE: FORMAÇÃO CONTINUADA; PROFESSORES; ESCOLA; PRÁTICA EDUCATIVA.

\begin{abstract}
The text aims to reflect on studies by theorists about the phenomenon of continuing education centered on school. The theoretical research now presented, is part of one of the sections of my doctoral thesis, entitled "Continuing Education of Teachers of Elementary Education Centered at School: perceptions of teachers and trainers of improvement of pedagogical practice", defended in 2019, by the University Federal do Pará. For this purpose, through a bibliographic search, we seek to situate the conceptual debate regarding the continuing education of teachers centered on the school. The studies carried out show that the continuous training of teachers centered on the school is a formative model, which is based on the training needs of the teachers, the school and the community with a view to a constant process of reflection on the educational practice, the teaching knowledge, the school experiences and the reality of the school.
\end{abstract}

1 Faculdade Estácio Macapá 
KEYWORDS: CONTINUING EDUCATION; TEACHERS; SCHOOL; EDUCATIONAL PRACTICE.

\section{RESUMEN}

El texto tiene como objetivo reflexionar sobre los estudios de los teóricos sobre el fenómeno de la educación continua centrada en la escuela. La investigación teórica ahora presentada es parte de una de las secciones de mi tesis doctoral, titulada "Educación continua de docentes de educación primaria centrada en la escuela: percepciones de docentes y formadores de mejora de la práctica pedagógica", defendida en 2019 por la Universidad Federal do Pará. Para ello, a través de una búsqueda bibliográfica, buscamos situar el debate conceptual sobre la formación continua de docentes centrados en la escuela. Los estudios realizados muestran que la formación continua de docentes centrados en la escuela es un modelo formativo, que se basa en las necesidades de formación de los docentes, la escuela y la comunidad con vistas a un proceso constante de reflexión sobre la práctica educativa, el conocimiento docente, el experiencias escolares y la realidad de la escuela.

PALABRAS CLAVE: EDUCACIÓN CONTINUA; MAESTROS; ESCUELA; PRÁCTICA EDUCATIVA.

\section{INTRODUÇÃO}

Atualmente é possível constatar um crescimento no número de publicações, envolvendo, como tema central, a formação continuada dos professores centrada na escola, embora, ainda, se possa afirmar que as pesquisas nessa área sejam relativamente novas no Brasil e que esse é um tema sobre o qual há muito a investigar.

Assim, a partir desta pesquisa, verificamos que há muito vem se desenvolvendo estudos, reflexões e conhecimentos sobre a formação continuada de professores centrada na escola, tendo em vista concepções de formação a partir de uma perspectiva reflexiva. Não é novo o pensamento de que uma das funções da escola é ser o lugar do desenvolvimento do pensar, visto que se trata de uma capacidade que pode ser desenvolvida, estimulada, aperfeiçoada, especialmente no âmbito da educação formal.

Autores, como: Canário (2005); Silva (2001); Gama (2013); Imbernón (2009); Cunha e Prado (2010); Candau (2011); Deák (2010); Almeida (2015); Placco e Souza (2015); Piatti (2006); Pimenta (2009, 2006); Nunes (2018); entre outros, relatam a importância de se pensar a formação continuada centrada na escola como um processo de constante reflexão sobre a própria prática, ou seja, de uma formação reflexiva e emancipadora, realizada de maneira crítica e autônoma, que valorize não 
só a formação em si, mas o pensamento e a experiência do professor como elementos essenciais na construção de novos saberes e competências profissionais, ou seja, o papel da reflexão na prática docente no aprimoramento do trabalho.

Essas pesquisas asseguram a ideia de que a escola é um espaço que também forma o professor. É considerada um ambiente privilegiado para atender uma diversidade de profissionais, sejam eles no início, no meio ou em fim de carreira, mas que carregam consigo uma vasta experiência profissional.

O objetivo ora proposto está em fazer uma reflexão acerca de estudos e pesquisas que focalizam a formação continuada de professores centrada na escola, tanto no contexto internacional como seara brasileira. Vale frisar, que o texto, que ora apresentamos, compõe uma das seções de minha tese de doutorado, defendida no ano de 2019, pela Universidade Federal do Pará.

Para tanto por meio de uma pesquisa bibliográfica buscamos situar o debate conceitual a respeito da formação continuada de professores centrada na escola. Nesse sentido, tomamos a formação continuada centrada na escola como aquela que parte das necessidades formativas do professor da escola, da comunidade e da reflexão da prática educativa, tendo em vista melhorá-la ao considerar os saberes docentes, as experiências pedagógicas e a realidade escolar.

\section{REFLEXÕES TEÓRICO-ESPECIALIZADAS DA FORMAÇÃO CONTINUADA DE PROFESSORES CENTRADA NA ESCOLA}

A formação continuada de professores tem sido percebida atualmente como um processo constante de qualificação dos docentes para prepara-los para o exercício do magistério. Nesse sentido, tem ganhado relevância nas discussões, nos debates e nas pesquisas na área da educação, tanto em nível internacional como nacional.

Observamos que a Formação Continuada de Professores (FCP), adotada nas escolas públicas, via de regra, se apresenta em uma perspectiva clássica, valendose da oferta de cursos, palestras, seminários, entre outras modalidades de formação, trabalhadas de forma pontual, breve, de baixo custo para o sistema educacional e descontextualizada da prática docente, o que contribui por levar o professor a participar obrigatoriamente do processo formativo apenas de "corpo presente", fato que tal formação perde sua relevância.

No centro de um novo pensamento está a formação continuada de professores centrada na escola. Ao buscar se distanciar de um modelo clássico de formação, esta parte das necessidades formativas dos professores e da reflexão da prática educativa, tendo em vista melhorá-la ao considerar os saberes docentes, as experiências pedagógicas e a realidade escolar. Este modelo chama à atenção de pesquisadores 
da área educacional que vêm desenvolvendo estudos, discussões qualificadas na seara educacional com relação a esta questão.

Nesse sentido, vemos ser oportuno destacar algumas compreensões de pesquisadores acerca do que definem como formação centrada na escola. Cunha e Prado (2010) descrevem a formação continuada centrada na escola, como:

Aquela que acontece no contexto de trabalho, privilegiando a colaboração, a interlocução sobre as práticas, as necessidades e os interesses dos professores que participam da construção e da gestão do plano de formação e são corresponsáveis pelo seu desenvolvimento. (CUNHA; PRADO, 2010, p. 102).

A formação continuada de professores centrada na escola é uma concepção de formação que se contrapõe ao modelo clássico de formação, tal qual definido por Candau (2011a), como aquele que é baseado em cursos planejados e organizados hierarquicamente e distantes da realidade dos professores e da escola, que sobrevaloriza as necessidades formativas dos professores tornando-a a-histórica.

A perspectiva da formação continuada centrada na escola tem como foco, segundo Piatti (2006, p. 39), "[...] a valorização dos conhecimentos dos professores oportuniza que eles sejam participantes do processo de elaboração dos programas de formação continuada e que suas práticas sejam valorizadas e sirvam como elemento de reflexão para construção de novas teorias". Por isso, [...] A ideia de formação, tendo como ambiente a escola, traz novas perspectivas de mudanças na formação docente. A escola, nesse sentido, é vista como lugar onde se estuda e exerce o direito de aprender a aprender. A sala de aula é o lócus de concretização da atividade profissional do professor. (PIATTI, 2006, p. 39).

No entendimento de Imbernón (2009), a formação continuada centrada na escola ambiciona fortalecer um modelo formativo colaborativo entre os professores. Tal modelo toma a escola como essência do processo "ação-reflexão-ação". Esse modelo formativo conjectura a restauração da organização da cultura escolar, pleiteia novos valores, na colaboração, no processo de participação, respeito e reconhecimento do poder e capacidade dos professores, redefinindo e ampliando a gestão escolar.

Piatti (2006, p. 40, grifos da autora) defende a tese da formação no interior da escola, pois tem a convicção que é o "[...] lugar no qual o professor vivencia a complexidade de sua prática. A instituição vista como nicho ecológico para o desenvolvimento e a formação "valoriza os saberes docentes e insiste na articulação entre prática e teoria". A referida autora pondera que a formação, estabelecida no contexto da escola, assegura ao professor qualificar-se "[...] diante das situações de trabalho que o levam a indagar, investigar sua ação e posteriormente buscar soluções para novas posturas e atitudes. 
O esforço da reflexão gera necessidade de que o professor colabore com os colegas e construa novos conhecimentos" (PIATTI, 2006, p. 40). Nessa compreensão, [...] A formação no ambiente de trabalho poderá superar a formação baseada na racionalidade técnica vivenciada pelos professores na formação inicial e muitas vezes em sua trajetória de formação continuada.

Nessa perspectiva, a prática do professor é vista como espaço privilegiado de produção de saberes e o processo de reflexão é visto como aprendizagem do professor, pois, ao refletir a ação, busca rever suas atitudes e posturas frente ao sistema de ensino e às especificidades de sua prática. (PIATTI, 2006, p. 41).

Vale asseverar, que o contexto da escola, carrega hodiernas discussões em torno das necessidades de reflexões críticas acerca das experiências, dos saberes e das práticas, como caminhos promissores para o desenvolvimento profissional e qualitativo dos professores, como caminhos possíveis para a melhoria da prática educativa.

Almeida (2015, p.10) enfatiza em seus estudos que a formação continuada, centrada na escola é "[...] uma das medidas mais coerentes, de maior valorização do saber do professor, de maior envolvimento da escola na tentativa de melhorar a qualidade do ensino". Em estudo de Canário (2005) é encontrada a seguinte referência sobre a formação continuada centrada na escola:

A pertinência da "formação centrada na escola" tem como base o pressuposto de que os professores aprendem a sua profissão nas escolas e que essa aprendizagem coincide com um processo largo, contínuo e multiforme, de socialização profissional que comporta modos e vertentes deliberados (formais) e não deliberados (informais). Centrar a formação (socialização deliberada) na escola significa, de algum modo, formalizar o informal, conferindo um caráter intencional e consciente àquilo que, normalmente, não o é: o processo de socialização difusa que está presente no exercício do trabalho. (CANÁRIO, 2005, p.137, grifos do autor).

Placco e Souza (2015b) corroboram com essa discussão quando concebem a formação centrada na escola, como:

Aquela que parte de suas demandas, mas não acontece só e necessariamente em seu interior. A complexidade da escola deriva não só de suas práticas, mas de todas as relações que profissionais e alunos estabelecem entre si, com a Secretaria de Educação, com os sistemas de ensino, com as políticas públicas, com a literatura, com a família e com a comunidade. Desse modo, a escola sofre influências de muitos aspectos que estão fora dela e que precisam ser considerados nos processos de formação. (PLACCO; SOUZA, 2015, p. 26).

Silva (2001), ao conceituar a formação continuada de professores centrada na escola, a defini como aquela que: 
[...] caracteriza-se por um processo contínuo de ação-reflexão-ação, que leva um crescimento pessoal e profissional dos professores e ao êxito da prática pedagógica, que demonstra, na realidade, o surgimento de um novo tipo de escola. Essa experiência pressupõe um salto qualitativo, fundamentado na concepção dialética de educação, em que procura alcançar novas finalidades do processo educativo por meios mais adequados eficazes, com profundas mudanças no sistema educacional. (SILVA, 2001, p.10).

Como é possivel verificar, o tema da formação continuada centrada na escola é uma questão que vem sendo recorrente nas discussões sobre a formação continuada de professores e tem sido foco de atenção de pesquisas na área educacional.

Cunha e Prado (2010) escreveram acerca da formação centrada na escola um pequeno opúsculo, intitulado Formação centrada na escola: desenvolvimento pessoal e profissional de professores. É um estudo teórico que tem como objetivo tematizar o conceito e a potencialidade da formação centrada na escola como modalidade de formação continuada de professores, na expectativa de contribuir para os debates sobre a formação, promovida no Horário de Trabalho Pedagógico Coletivo (HTPC). O estudo problematiza a formação centrada na escola, concebida como a que acontece no contexto de trabalho, privilegia a colaboração e a interlocução entre professores.

Para Cunha e Prado (2010), a formação centrada na escola, apodera-se da prática como referência para análise, reflexão e crítica com base nos saberes que o professor já construiu na sua vivência docente e a pesquisa como mecanismo formativo e situação privilegiada para organização dos conhecimentos e experiências arquitetadas no interior da escola.

Cunha e Prado (2010, p. 104, grifos dos autores) argumentam, ao longo de seus estudos, que a formação continuada de professores centrada na escola, "[...] é aquela que acontece no interior da escola, nomeada aqui de "formação centrada na escola" ou "formação em contexto", apresenta-se como perspectiva para ressignificar o Horário de Trabalho Docente Coletivo - HTDC".

Silva (2001), ao pesquisar sobre o objeto da formação continuada centrada na escola, destaca que no Brasil existe uma quase ausência de políticas e programas voltados a esta finalidade. Assim, infere que:

Pouco se conhece das várias experiências educacionais como as dos "ginásios estaduais vocacionais" e as "escolas estaduais experimentais", que apresentavam propostas alternativas de renovação pedagógica e demonstravam que a melhor formação continuada é a que se dá em serviço ou na própria instituição em que o professor atua. (SILVA, 2001, p. 9, grifos do autor).

Para Silva (2001, p. 9), a formação continuada de professores centrada na instituição escola "[...] é uma formação que favorece a reflexão sobre a própria prática e possibilita o aprofundamento dos fundamentos teóricos, a correção das distorções 
e a diminuição das defasagens em relação às finalidades, com o encaminhamento coletivo de soluções para os problemas emergentes".

O estudo de Deák (2010), intitulado A formação centrada na escola: o que pensam os professores da rede municipal de ensino de Presidente Prudente, teve como base uma pesquisa de campo, cujo objetivo foi o de mapear o perfil dos profissionais da Educação Infantil e $1^{\circ}$ ciclo do Ensino Fundamental e diagnosticar as condições de formação e atuação dos docentes no município de Presidente Prudente. Numa primeira fase da pesquisa, foi realizada a aplicação de questionários para os professores de todas as Escolas Municipais de Presidente Prudente.

O texto de Deák (2010) traz a análise referente às questões que dizem respeito às concepções dos professores da Educação Infantil e do Ensino Fundamental (10 ciclo) sobre a Formação Centrada na Escola, Horário de Trabalho Pedagógico Coletivo (HTPC), assim como a sua adequação e necessidade de mudança. De acordo com as categorias estabelecidas para o estudo, a autora concluiu que a formação centrada na escola, na percepção dos professores, é considerada como atividades internas para resolução de problemas da escola e de atividades internas gerais que tratam de todos os assuntos. Quanto ao momento do HTPC, estes são indicados predominantemente como momento de troca de experiências entre os docentes e momento de estudo, reflexão e planejamento, considerando esse momento, um espaço formativo na escola. No que diz respeito à adequação e necessidades dos momentos de formação centrada na escola, apontam prioritariamente, a questão da organização desse momento, que necessita ser repensada.

Vale ressaltar também a pesquisa de Gama (2013) que trata sobre "A Formação Contínua Docente Centrada na Escola: contributos para um desenvolvimento pessoal, profissional e organizacional". Este foi um estudo de natureza qualitativa, junto a um agrupamento de Escolas Públicas, com o uso de entrevistas semiestruturadas, abrangendo docentes hierarquicamente organizados desde o topo (gestão), passando pela gestão intermédia até à base (docentes sem cargo atribuído).

Das conclusões apontadas no estudo de Gama (2013), podemos destacar o fato de os professores concordarem que a formação contínua centrada na escola é um fator de desenvolvimento pessoal, profissional e organizacional, contudo os achados mostram que, na prática, os professores admitem que a implementação desse modelo de formação implica várias limitações e constrangimentos; reconhecem que as políticas educativas, nomeadamente as emanadas quanto à formação contínua constituem um dos principais constrangimentos à implementação deste modelo de formação; mas entendem serem necessárias no futuro mudanças profundas nesse domínio. 
Estudo doutoral recente que toma a formação continuada de professores centrada na escola como objeto de estudo é o de Nunes (2018), intitulado Formação continuada de professores do ensino fundamental centrada na escola: reflexão e pesquisa-ação para mudanças de concepções e práticas de alfabetização e letramento. $\mathrm{O}$ referido estudo buscou articular em um mesmo processo, investigação e formação continuada. Para tanto, objetivou desenvolver e analisar uma prática de formação contínua de professores alfabetizadores centrada na escola, tendo em vista a mudança de concepções e práticas, assim como desenvolver e analisar uma prática de pesquisa-ação centrada na escola à luz do paradigma reflexivo e do professor pesquisador.

A produção de dados da pesquisa de Nunes (2018) prevaleceu-se de diferentes técnicas utilizadas por ocasião da formação, bem como da pesquisa-ação desenvolvida pelas professoras. Entre elas: entrevistas, sessões de formação/reflexão, observação participante e análise documental. Os resultados do estudo indicaram que tanto a formação contínua quanto a pesquisa-ação, desenvolvidas pelas professoras desenvolvidas no contexto escolar, constituíram-se a primeira experiência formativa e científica que participaram, o que as conduziu a uma dinâmica formativa reflexiva contínua de suas práticas alfabetizadoras o que provocou transformações importantes na sua forma de perceber as práticas alfabetizadoras, contribuindo na qualidade do trabalho pedagógico, bem como nas aprendizagens alfabetizadoras dos alunos. Nunes (2018, p.6) conclui também, em seus estudos, que:

[...] não só é possível, mas desejável, que os professores atuem como conceptores, planejadores, organizadores e gestores de projetos formativos e de pesquisa que visem à melhoria de suas práticas; que quando o projeto de formação contínua em serviço é gestado, associado ao projeto educativo da escola e parte das necessidades formativas dos professores, tende a ser mais legitimada por eles; que práticas colaborativas entre a escola e a universidade podem constituir-se como agenda promissora entre as instituições envolvidas como condição fundamental para o processo de desenvolvimento pessoal e profissional de professores, principalmente no âmbito paraense e que a formação continuada centrada na escola e as pesquisas desenvolvidas como atividades sistemáticas no interior da escola são ainda um grande desafio aos professores no contexto paraense devido às precárias condições de trabalho bem como a representação de que tais atividades são um trabalho acrescido.

Nunes (2018) pondera que não é tarefa fácil quando a insuficiente clareza dessa formação pela inexistência de um projeto de formação (objetivos, métodos, conteúdo e princípios), articulado com o projeto educativo da escola, representa um obstáculo à continuidade do processo formativo dos professores porque mantém e intensifica as representações dos professores de que esta formação não é motivadora para a melhoria de suas práticas e formação. "[...] Desenraizada do contexto e obscura 
para muitos docentes quanto às finalidades dela, a dúvida, portanto, a desconfiança da eficácia da formação contínua para a melhoria de suas práticas, torna-se legítima". (NUNES, 2018, p. 52). Assim,

[...] A formação contínua de professores centrada na escola [...] obedece a uma lógica diferente desta, contrapondo-se a uma lógica de catálogo, com oferta de ações eventuais, avulsas e esporádicas, para uma lógica de projeto formativo em um continuum articulado ao projeto educativo da escola tendo em vista o desenvolvimento pessoal e profissional dos professores e o desenvolvimento organizacional das escolas. Desta forma, a questão que se põe para o debate e reflexão nesta tese diz respeito não à quantidade de formação, mas à qualidade dela expressa em um projeto global de formação a longo prazo. (NUNES, 2018, p. 51-52).

Podemos, então, entender que a formação continuada centrada na escola é aquela que privilegia o próprio contexto de trabalho do professor, isto é, um modelo formativo que integra as ações práticas dos professores, considerando suas necessidades e seus interesses dos quais são partícipes do desenvolvimento desse processo formativo no ambiente escolar. Modelo formativo este que vem ganhando espaço nos debates sobre a formação contínua de professores.

Devemos perceber a escola como um lócus de múltiplas e diversificadas aprendizagens para todos os protagonistas que estão implicados no processo educativo, aprendizagens essas, que os professores erigem. Assim, é preciso que os programas de formação possibilitem aos professores o exercício da autonomia, a reflexão sobre as situações e os problemas da realidade profissional, como a percepção de que as teorias aliadas às práticas permitem avançar seus conhecimentos, compreender que, também, são responsáveis pela sua formação e dos colegas, num movimento dialético entre a participação e a colaboração (PIMENTA, 2009). Logo,

[...] A formação envolve um duplo processo: o de auto formação dos professores, a partir da reelaboração constante dos saberes que realizam em sua prática, confrontando suas experiências nos contextos escolares; e o de formação nas instituições escolares onde atuam. Por isso, é importante produzir a escola como espaço de trabalho e formação. (PIMENTA, 1999, p. 30).

Podemos então afirmar, que o desenvolvimento da FCP que oportunize aos docentes espaços de reflexão acerca da realidade cotidiana em seu próprio lócus de trabalho é fundamental para o processo de qualificação da prática pedagógica deles. Isso reforça a ideia de que a formação continuada centrada na escola que considera as necessidades formativas dos professores e da escola, revela-se um caminho promissor para o desenvolvimento profissional do professor e contribui para a melhoria da prática pedagógica. 
Nesse contexto, vale ratificar que tornar a escola como espaço privilegiado de formação continuada de professores em serviço, não significa tirar a responsabilidade do Poder Público em investir em programas de qualificação para seus professores na escola ou em outros terrenos.

Embora pesquisas (PIMENTA, 2006) mostrem a importância da formação crítico reflexiva, sua prática ainda é pouco difundida, pois alguns empecilhos dificultam a participação dos professores em uma formação centrada na escola. Os obstáculos são muitos para congregar uma coletividade de professores para usufruir da dinâmica de formação que centra-se na escola, torna o modelo pouco exequível nas escolas, sobretudo devido a organização do tempo escolar se sobrepor ao tempo formativo. Outro obstáculo é a ausência fomento dos sistemas de ensino e a extensa jornada de trabalho, aos quais os professores são subordinados. Estes são aspectos que advogam significativamente de forma negativa para a realização desta prática formativa na escola.

Dessa maneira, a partir do pressuposto de que a formação continuada de professores centrada na escola se insere na perspectiva de uma formação reflexiva, que fomenta a escuta das necessidades formativas cotidianas do professor, permitindo a livre expressão de seus conhecimentos, seus medos, suas angústias, proporcionando novas aprendizagens por intermédio de momentos de reflexão e de trocas colaborativas e emancipatórias com vistas à melhoria da prática pedagógica.

As preocupações com a transformação das práticas formativas de professores têm ocupado parte significante das pesquisas educacionais e é nesse movimento que esta pesquisa se insere no sentido de propiciar uma incursão no terreno da formação continuada centrada na escola. Tal incursão passou constitui-se como uma nova forma de olhar/analisar práticas pedagógicas, em relação ao processo de formação continuada de professores no âmbito escolar ou em outras agências formadoras, constituindo-se a um só tempo, a maneira de relatar muitos entendimentos sobre este processo formativo no interior das escolas.

Assim, vale sublinhar que este estudo não tem a intenção de desapreço a outros espaços de formação continuada de professores em detrimento do processo realizado na escola. Temos a convicção que a formação continuada de professores centrada na escola, para além de uma preocupação na (re)apropriação de conteúdos relacionados à disciplinas específicas, mas, proposta a partir de demandas, necessidades formativas, que se caracterizam como conteúdos interdisciplinares, necessários ao alcance dos objetivos da escola e desenvolvimento de seu papel social, apresentam fortes indícios que podem contribuir pra a melhoria da prática pedagógica dos professores e consequentemente para o processo educativo como 
um todo, de modo a legitimar a escola, mesmo em termos de índices de avaliação institucionalmente.

\section{CONSIDERAÇÕES FINAIS}

Considerando as reflexões acerca dos estudos dos autores analisados, percebe-se que a formação continuada de professores, apresenta-se como um modelo de formação continuada que vem apresentando grande aceitação por parte das práticas educativas, mas que no entanto precisa de uma atenção maior por parte das políticas públicas para que este modelo formativo se concretize nas instituições de ensino política escolar de formação, pois apesar de uma realidade muito ainda precisa ser divulgado e discutido acerca desta questão.

Desse modo, a formação contínua centrada na escola, no contexto brasileiro ainda é um caminho a ser percorrido no interior das escolas, face às eternas dificuldades que estas encontram para elaborar e desenvolver, sem a tutela das secretarias de ensino, um processo de formação contínua de professores, principalmente porque tais escolas pouco têm, por exemplo, autonomia didático-financeira para proporem e realizarem no seu tempo e em condições satisfatórias, um dado programa de formação contínua.

Portanto, a "formação centrada na escola" constitui hoje um referencial atual e importante a ser considerado ao pensar os sistemas educacionais e as escolas de uma forma geral, tendo em vista atender as necessidades da formação dos professores. Tais necessidades devem ser analisadas e avaliadas com base nos problemas vivenciados a partir da escola e de seu projeto educativo construído com a participação de todos os seus atores.

\section{REFERÊNCIAS}

ALMEIDA, Laurinda Ramalho de. Formação centrada na escola: das intenções às ações. In: ; PLACCO, Vera Maria Nigro de Souza (org.). O coordenador pedagógico e a formação centrada na escola. 2. ed. São Paulo: Edições Loyola, 2015a. p. 9-24.

CANÁRIO, Rui. O que é a escola? Um "olhar" sociológico. Porto: Porto, 2005.

CANDAU, Vera Maria. Pluralismo Cultural, Cotidiano Escolar e Formação de Professores. In: (org.). Magistério: construção cotidiana. Petrópolis: Vozes, 2011a. p. 237-250. 
DEÁK, Simone Conceição Pereira. A formação centrada na escola: o que pensam os professores da rede municipal de ensino de Presidente Prudente. X CONGRESSO NACIONAL DE EDUCAÇÃO, 10., 2011, Curitiba; SEMINÁRIO INTERNACIONAL DE REPRESENTAÇÕES SOCIAIS, SUBJETIVIDADE EDUCAÇÃO - SIRSSE, 1., 2011, Curitiba. Anais [...]. Curitiba: Pontifícia Universidade católica do Paraná, 2011. Disponível em: educere.bruc.com.br/CD2011/pdf/5666_3759.pdf. Acesso em: 3 out. 2018.

CUNHA, Renata Cristina Oliveira Barrichelo; PRADO, Guilherme do Val Toledo. Formação centrada na escola, desenvolvimento pessoal e profissional de professores.

Revista de Educação PUC-Campinas. Campinas, n. 28, p.101-111, jan./jun., 2010. Disponível em: file://C:/Users/JOÃO\%20VICTOR/AppData/Local/Packages/ Microsoft.MicrosoftEdge_8we kyb3d8bbwe/TempState/Downloads/79-186-1-SM\%20 (3).pdf. Acesso em: 3 out. 2018.

GAMA, Natalina Maria Marques Cravo. A formação contínua docente centrada na escola: contributos para um desenvolvimento pessoal, profissional e organizacional. 2013. Dissertação (Mestrado em Supervisão Pedagógica) - Faculdade de Ciências Sociais e Humanas, Universidade da Beira Interior, Covilhã, 2013.

IMBERNÓN, Francisco. Formação docente e profissional: formar-se para a mudança e a incerteza. 7. ed. São Paulo: Cortez, 2009. (Coleção Questões da Nossa Época).

NUNES, Hérika Socorro Costa. Formação continuada de professores do Ensino Fundamental centrada na escola: reflexão e pesquisa: ação para a mudança de concepções e práticas de alfabetização e letramento. Tese (Doutorado em Educação) Instituto de Educação, Universidade de Lisboa, Lisboa, 2018. (Documento Provisório).

PIATTI, Célia Beatriz. Formação continuada: reflexos na prática dos professores participantes do Programa de Formação de Professores Alfabetizadores - PROFA. Dissertação (Mestrado em Educação) - Universidade Católica Dom Bosco, Campo Grande, Mato Groso do Sul, 2006.

PIMENTA, Selma Garrido (org.). Saberes pedagógicos e atividade docente. São Paulo. Cortez, 1999.

. Professor reflexivo: construindo uma crítica. In: ; GHENDIN, Evandro (org.). Professor reflexivo no Brasil: gênese e crítica de um conceito. 4. ed. São Paulo: Cortez, 2006. p. 17-52. 
PLACCO, Vera Maria Nigro de Souza; SOUZA, Vera Lúcia Trevisan de. Entraves da formação centrada na escola: possibilidades de superação pela parceria da gestão na formação. In: PLACCO, Vera Maria Nigro de Souza; ALMEIDA, Laurinda Ramalho de (org). $O$ coordenador pedagógico e a formação centrada na escola. 13. ed. São Paulo, SP: Edições Loyola, 2015. p. 25-44.

SILVA, Moacyr da. A formação do professor centrada na escola: uma introdução. São Paulo: EDUC, 2001.

\section{SOBRE O AUTOR}

JUDENILSON TEIXEIRA AMADOR. Doutor em Educação pela Universidade Federal do Pará; Mestre em Direito Ambiental e Políticas Públicas pela Universidade Federal do Amapá; Especialista em Didática do Ensino Superior e Gestão do Trabalho Pedagógico; Professor Auxiliar da Faculdade Estácio Macapá; Professor Horista da Faculdade de Tecnologia e Ciências Humanas; Funcionário Público do Estado do Amapá na condição de Professor. Integrante do Grupo de Estudos, Pesquisas e práticas na Amazònia Amapaense - GEPEA.

RECEBIDO: 05/04/2020.

APROVADO: 07/04/2020. 